\title{
Development of a Novel Bi-Enzymatic Nanobiocatalyst for the Efficient Bioconversion of Oleuropein to Hydroxytyrosol
}

\author{
Archontoula Giannakopoulou ${ }^{1}$, Alexandra V. Chatzikonstantinou ${ }^{1}\left({ }^{\circledR}\right.$, Nikolaos Chalmpes $^{2} \oplus$, Georgia Tsapara $^{1}$, \\ Dimitrios Gournis ${ }^{2}{ }^{(1)}$, Angeliki C. Polydera ${ }^{1}$ and Haralambos Stamatis $1, *(1)$ \\ 1 Biotechnology Laboratory, Department of Biological Applications and Technologies, University of Ioannina, \\ 45110 Ioannina, Greece; arxontoula.gian@gmail.com (A.G.); alexandra_xatzi@hotmail.com (A.V.C.); \\ geo.tsapara@gmail.com (G.T.); apolyder@uoi.gr (A.C.P.) \\ 2 Department of Materials Science \& Engineering, University of Ioannina, 45110 Ioannina, Greece; \\ chalmpesnikos@gmail.com (N.C.); dgourni@uoi.gr (D.G.) \\ * Correspondence: hstamati@uoi.gr; Tel.: +30-2651007116
}

check for

updates

Citation: Giannakopoulou, A.; Chatzikonstantinou, A.V.; Chalmpes, N.; Tsapara, G.; Gournis, D.; Polydera, A.C.; Stamatis, H. Development of a Novel Bi-Enzymatic Nanobiocatalyst for the Efficient Bioconversion of Oleuropein to Hydroxytyrosol. Catalysts 2021, 11, 749. https:// doi.org/10.3390/catal11060749

Academic Editor: Nan Cheng

Received: 29 May 2021

Accepted: 16 June 2021

Published: 19 June 2021

Publisher's Note: MDPI stays neutral with regard to jurisdictional claims in published maps and institutional affiliations.

Copyright: (c) 2021 by the authors. Licensee MDPI, Basel, Switzerland. This article is an open access article distributed under the terms and conditions of the Creative Commons Attribution (CC BY) license (https:// creativecommons.org/licenses/by/ $4.0 /)$.

\begin{abstract}
Lipase A from Candida antarctica (CalA) and $\beta$-glucosidase from Thermotoga maritima (bgl) were covalently co-immobilized onto the surface of chitosan-coated magnetic nanoparticles (CS-MNPs). Several parameters regarding the co-immobilization procedure (glutaraldehyde concentration, incubation time, CS-MNPs to enzyme mass ratio and bgl to CalA mass ratio) were evaluated and optimized. The developed nanobiocatalyst was characterized by various spectroscopic techniques. Biochemical parameters such as kinetic constants and thermal stability were also evaluated. The nanobiocatalytic system revealed an increase in the $K_{m}$ constant followed by a decrease in $V_{\max }$ value compared with the native enzymes, while a significant increase ( $>5$-fold higher) of the thermal stability of the immobilized CalA, both in individual and in co-immobilized form, was observed after $24 \mathrm{~h}$ incubation at $60^{\circ} \mathrm{C}$. Finally, the nanobiocatalyst was efficiently applied for the bioconversion of oleuropein to hydroxytyrosol, one of the most powerful naturally derived antioxidants, and it could be recycled for up to 10 reaction cycles ( $240 \mathrm{~h}$ of constant operation) at $60{ }^{\circ} \mathrm{C}$, retaining more than $50 \%$ of its initial activity.
\end{abstract}

Keywords: multienzyme co-immobilization; lipase A from Candida antarctica; $\beta$-glucosidase from Thermotoga maritima; chitosan-magnetic nanoparticles; nanobiocatalysis; oleuropein modification

\section{Introduction}

Oleuropein (OLE), a major bioactive phenolic antioxidant found in high concentrations in the olive tree Olea europaea, is responsible for the bitter taste of olive oil and fruit [1]. Its chemical structure consists of an ester bond between a molecule of elenolic acid (EA) and 3,4-dihydroxyphenylethanol or hydroxytyrosol (HT) and a glycosidic bond between the EA and the HT [2]. OLE is characterized by various biological activities, such as antimicrobial, antioxidant, anti-inflammatory and anticancer. It is also a well-known compound for its cardioprotective, neuroprotective and hypolipidemic activities, which establish OLE a potentially natural additive for cosmetics and medicine [3]. On the other hand, HT, the main degradation product of OLE, is considered one of the most powerful naturally derived antioxidants, exhibiting a plethora of biological activities, usually superior to OLE [4]. Apart from HT, other oleuropein's degradation products, such as the EA or the oleuropein aglycone, are also gaining increasing attention due to their significant biological properties. Oleuropein aglycone has been reported to exhibit many activities similar to those of oleuropein [5], while the secoiridoid, elenolic acid, has been recognized as an antiviral agent [6,7]. However, contents of HT are low in natural sources, and many challenges are revealed in its chemical synthesis, including the low final yield and the large number of toxic reagents and expensive catalysts required. 
The bioconversion of OLE to HT could be an optimal alternative over conventional chemical processes as a more environmentally friendly approach with higher conversion rates. Until now, a variety of hydrolytic enzymes including lipases, esterases, cellulases and xylanases has been reported for the efficient synthesis of HT from OLE [8]. Among them, $\beta$-glucosidases play a key role in the cleavage of the glycosidic bond of OLE, releasing glucose and its corresponding aglycone. Other enzymes, such as lipases or esterases, could subsequently initiate the breakage of the OLE ester bond, forming HT and an elenolic acid glucoside. The regioselective hydrolysis of oleuropein toward the production of the corresponding biologically active compounds has been recently reported using a free form of a commercial lipase and a thermophilic $\beta$-glucosidase from Myceliophthora thermophile [6]. However, the use of immobilized biocatalysts for the regioselective hydrolysis of OLE remains restricted and challenging and usually refers to individually immobilized enzymes [9]. However, the development of robust biocatalysts consisting of more than one enzyme is considered of high priority when referring to reactions that require the synergistic action of two or more enzymes, such as the bioconversion of oleuropein (Figure 1).

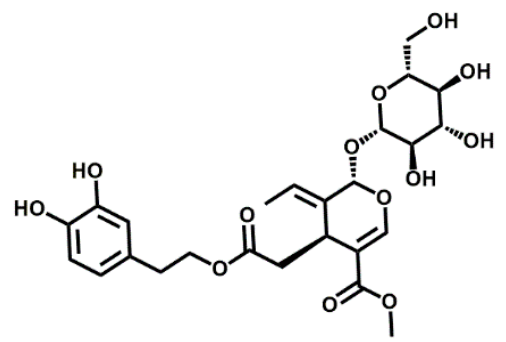

Oleuropein
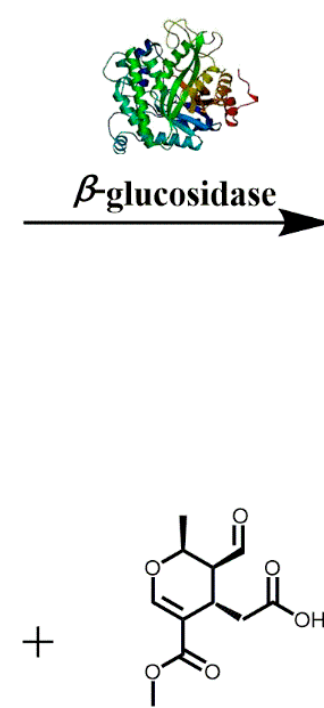

Elenolic acid<smiles>COC(=O)C1=COC(O)C2=COC(=O)CC12</smiles>

Oleuropein aglycon

Glucose<smiles>OCCc1ccc(O)c(O)c1</smiles>

Hydroxytyrosol

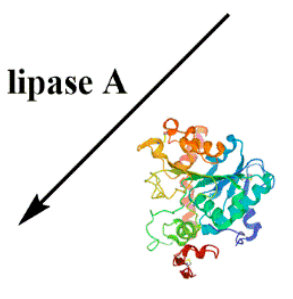

Figure 1. Bioconversion of oleuropein to hydroxytyrosol by bgl and CalA.

Multi-enzyme co-immobilization brings several free enzymes in proximity, so that a specific arrangement of the enzymes can be accomplished, leading to enhanced reaction rates compared to their free form. Moreover, the overall process is characterized by the elimination of reaction byproducts and intermediates and the reduction of diffusion losses, promoting high yields and atom economy [10,11]. Multi-enzyme biocatalytic systems could also offer many other advantages such as the possibility of artificially developing metabolic pathways that do not appear in nature as an alternative to conventional chemical synthesis for the production of high-value chemicals and bioproducts. Especially, under a catalytic point of view, multienzyme nanostructures present higher conversion rates when compared to enzymes immobilized on bulk materials due to their large surface-to-volume ratio [12].

Chitosan-coated magnetic nanoparticles (CS-MNPs) have been broadly used as promising nanocarriers for both single- and multi-enzyme immobilization of various enzymes [13-16] as they provide a plethora of multifunctional characteristics such as biocompatibility, nontoxicity, small size and superparamagnetism [17]. The easy separation of these nanocarriers, simple by applying an external magnet, facilitates the reuse of the 
nanobiocatalyst. Moreover, the chitosan coating of the magnetic nanoparticles provides their surface with new functional groups, such as primary amino and hydroxyl groups, which enables enzyme immobilization [18,19]. Glutaraldehyde is widely used as a crosslinking agent for the covalent immobilization of enzymes on nanocarriers rich in primary groups on their surface, such as chitosan. This agent has the ability to directly react with the primary amino groups of chitosan through the formation of Schiff bases and subsequently attaching enzymes on these groups in high yields. Moreover, as it has been reported [20], glutaraldehyde can cause enzyme attachment on primary hydroxyl groups at lower yields under acidic conditions.

The aim of this work was the development of a robust bi-enzymatic nanobiocatalytic system for the bioconversion of oleuropein to hydroxytyrosol. To this end, chitosan-coated magnetic nanoparticles were synthesized and used as a carrier for the co-immobilization of two enzymes, namely $\beta$-glucosidase from Thermotoga maritima ( $\mathrm{bgl}$ ) and lipase A from Candida antarctica (CalA). The choice of bgl was based on its a key role in the cleavage of the glycosidic bond of OLE [9], while CalA was chosen for its ability to modify a wide range of substrates, including long-chain fatty acids or voluminous substrates due to its peculiar structure [21]. The prepared bi-enzymatic nanobiocatalyst was characterized by various spectroscopic techniques, such as Fourier-transform infrared spectroscopy (FTIR) and fluorescence spectroscopy. Several parameters concerning the co-immobilization procedure were optimized, while many techniques were applied for the characterization of this bionanoconjugate with respect to its catalytic activity as well as its thermal and operational stability. To the best of our knowledge, this is the first time that a bi-enzymatic nanobiocatalyst consisting of $\beta$-glucosidase from Thermotoga maritima and lipase A from Candida antarctica co-immobilized onto chitosan-coated magnetic nanoparticles is applied for the efficient biotransformation of OLE to HT.

\section{Results and Discussion}

\subsection{Synthesis and Characterization of the Chitosan Magnetic Nanoparticles}

In the present study, iron magnetic nanoparticles $\left(\mathrm{Fe}_{3} \mathrm{O}_{4}\right)$ functionalized with chitosan were synthesized according to the ionic gelation method with sodium tripolyphosphate (TPP) as the crosslinking agent $[22,23]$. Various methods were applied for the characterization of the chitosan-coated magnetic nanoparticles, such as X-ray diffraction (XRD) and atomic force microscopy (AFM). The successful preparation of the CS-MNPs was evidenced with XRD (see Supplementary File, Figure S1), while their structural and morphological characterization was revealed by AFM.

\section{Atomic Force Microscopy (AFM)}

The structure and the morphology of the prepared $\mathrm{Fe}_{3} \mathrm{O}_{4}$ chitosan nanoparticles was revealed by atomic force microscopy (AFM). Representative AFM images of the hybrid system deposited on Si-wafer by drop casting from aqueous dispersions are presented in Figure 2, confirming the presence of spherical nanoparticles with a slightly disrupted circular morphology (Figure 2a,d). In addition, the phase depiction of the $\mathrm{Fe}_{3} \mathrm{O}_{4}$ chitosan nanoparticles as shown in Figure $2 b$ is indicative of the creation of a chitosan shell around the core of the magnetic nanoparticles. The size of the hybrid magnetic nanostructure as evaluated by AFM cross-sectional images was close to $50 \mathrm{~nm}$ (Figure 2c). 


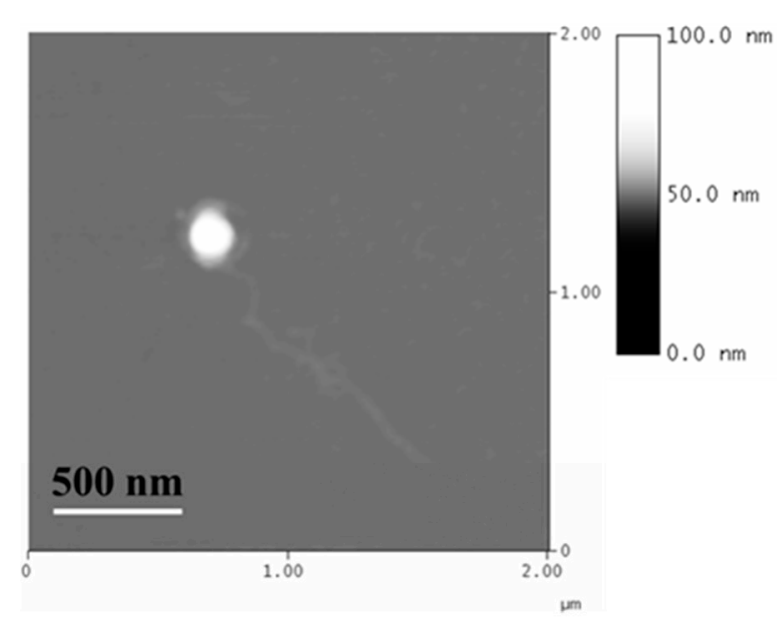

(a)
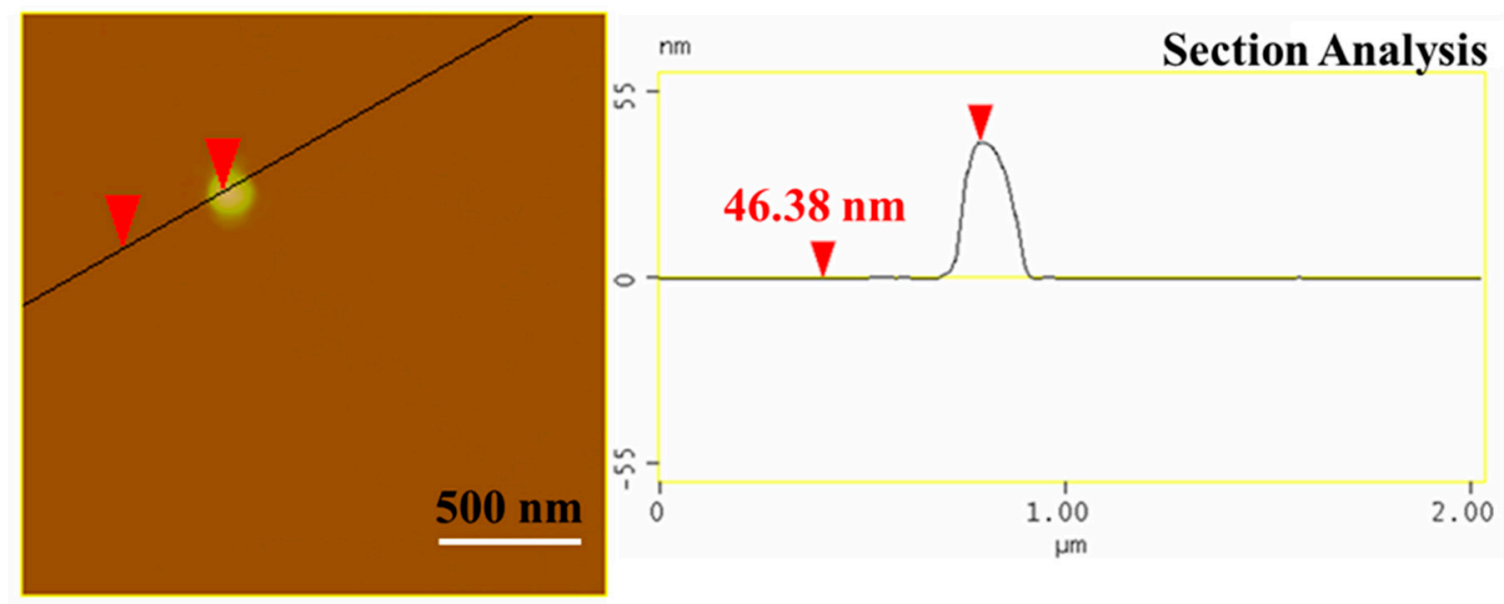

(c)

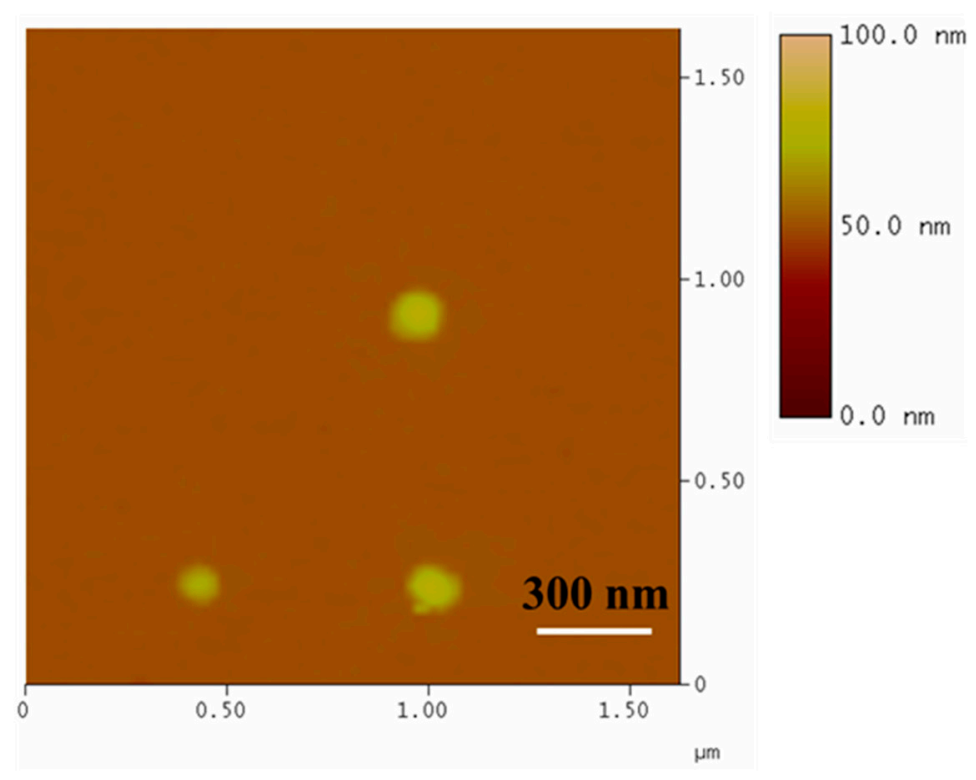

(d)

Figure 2. Atomic force microscopy (AFM) height (a,d); phase (b) and cross-section analysis (c) images of $\mathrm{Fe}_{3} \mathrm{O}_{4}$ chitosan nanoparticles. 


\subsection{Preparation of the Bi-Enzymatic Magnetic Nanobiocatalyst}

The hydrolytic enzymes bgl and CalA were covalently attached onto the surface of chitosan-functionalized magnetic nanoparticles by employing glutaraldehyde as a crosslinking agent. Several parameters affecting the co-immobilization yield such as the crosslinker concentration, the ratio of CS-MNPs to total enzyme mass, the ratio between bgl and CalA and the incubation time were examined and optimized. It has been reported that glutaraldehyde can directly affect enzyme loading and activity recovery of the enzymes after co-immobilization $[20,24]$. Therefore, the effect of glutaraldehyde concentration on enzymes activity recovery was investigated in the range of $5-20 \% v / v$, and the results are presented in Figure 3a. The enzymes activity recovery was determined by measuring the activity of the prepared nanobiocatalyst at different glutaraldehyde concentrations through the enzymatic assay for each enzyme (as described in Section 3.2.5). As it can be seen, at varying glutaraldehyde concentrations, the activity recovery of the enzymes was affected, yielding a maximum activity recovery at $10 \% v / v$ crosslinker concentration $(79 \%$ for $\mathrm{CalA}$ and $76 \%$ for $\mathrm{bgl})$. At higher or lower glutaraldehyde concentrations, the enzymatic activities were slightly reduced, probably because lower crosslinker concentrations may not be sufficient, while higher concentrations might cause conformational changes leading to a loss of enzymatic activity. These results are in agreement with previously reported studies $[25,26]$, reporting that significantly low or high glutaraldehyde concentrations lead to insufficient crosslinking of the enzymes, while enzyme activity recoveries tend to increase with increasing crosslinker concentrations up to a maximum value.

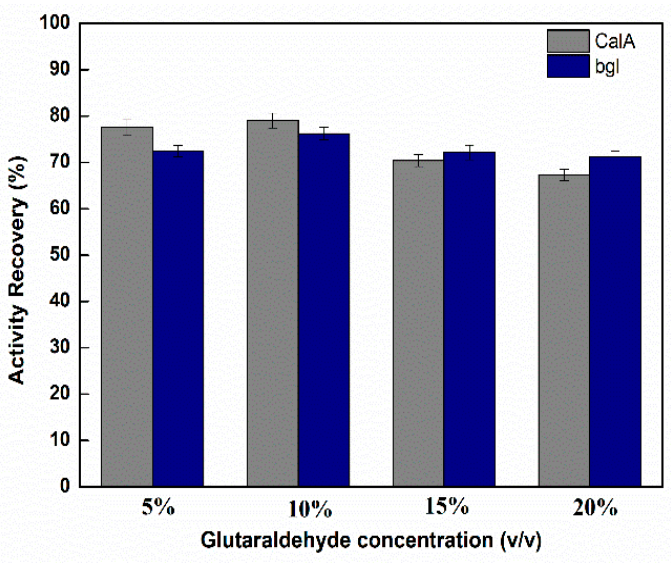

(a)

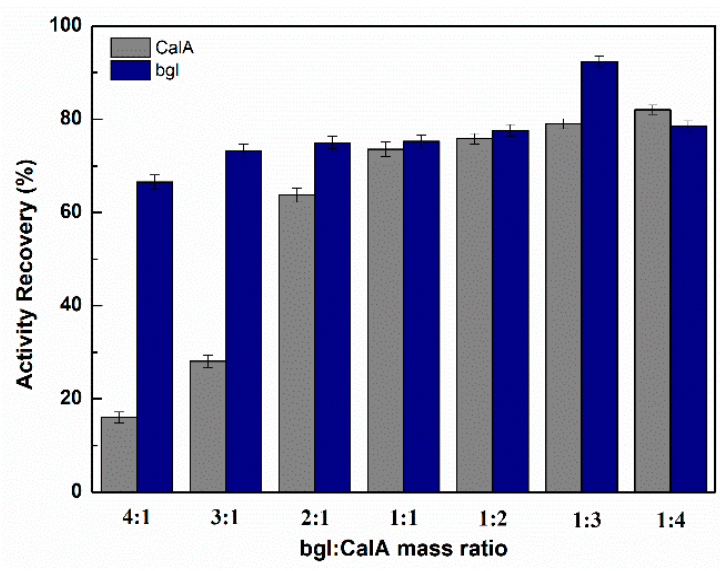

(c)

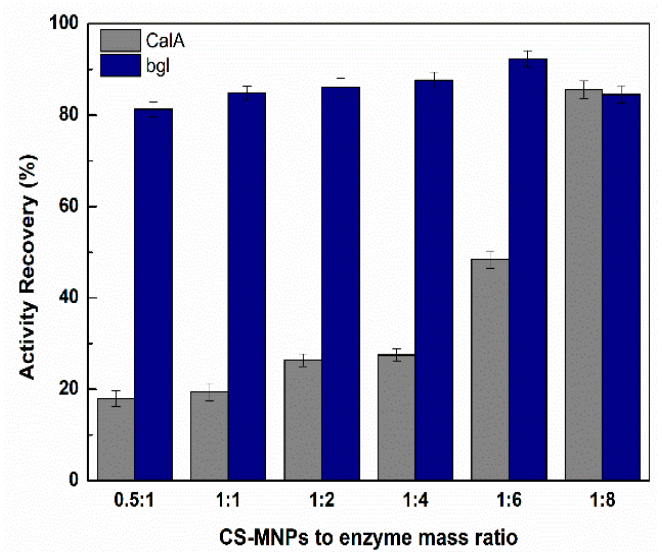

(b)

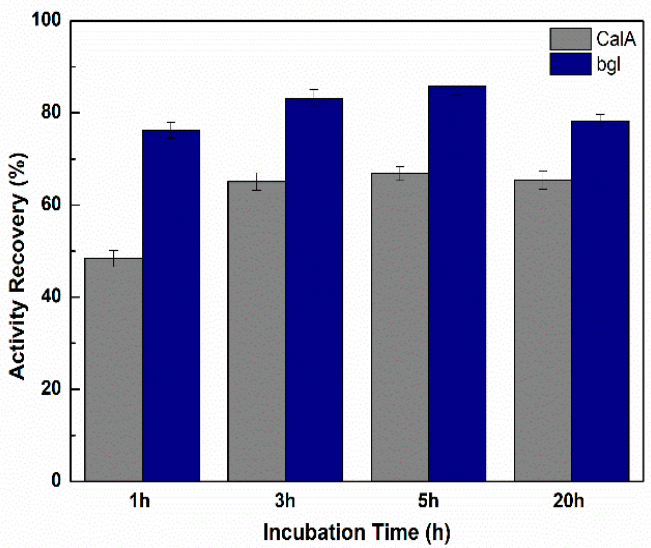

(d)

Figure 3. Effect of immobilization parameters on the activity recovery of the enzymes as a function of: (a) crosslinker concentration; (b) CS-MNPs to enzyme mass ratio; (c) bgl to CalA mass ratio and (d) incubation time. 
Subsequently, the effect of mass ratio of the nanocarrier to total enzyme content was investigated. More specific, the glutaraldehyde concentration was retained at $10 v / v$, while the mass ratio of the nanocarrier to total enzyme content was ranged from 0.5:1 to 1:8 (w/w). As shown in Figure 3b, the activity recovery of bgl does not seem to be strongly affected at different ratios of the nanocarrier, while the activity recovery of CalA is significantly affected by varying ratios, yielding in a maximum activity recovery $(85 \%)$ at 1:8 mass ratio. At lower mass ratios, sufficient surface area of the nanosupport to bind both enzymes may not be available, while at higher ratios, phenomena such as enhanced immobilization on the surface could be observed, consequently leading to steric hindrance amongst the enzymes, as previously described [27-29].

The ratio of bgl to CalA was also investigated with respect to its effect on the activity recovery. The ratio of bgl to CalA was tested in the range of $4: 1$ to $1: 4$, and the results are depicted in Figure 3c. It seems that the activity recovery of bgl is not significantly affected by the amount of CalA used for the co-immobilization process. However, the activity recovery of CalA seems to be strongly affected by the amount of bgl, yielding a maximum activity recovery $(82 \%)$ at a mass ratio of $1: 4$, namely when the amount of bgl used for the co-immobilization was four times lower than the amount of CalA. As it is illustrated in Figure 3c, when the amount of bgl was higher than CalA, a low activity recovery was observed for CalA, revealing possible competition effects between the two enzymes during the co-immobilization process. Similar results have been reported for the co-immobilization of cellulase and lysozyme on amino-functionalized magnetic nanoparticles [27], where the ratio effects of cellulase to lysozyme on the activities recovery of co-immobilized enzymes also revealed a competition between the two enzymes during co-immobilization.

Finally, the effect of incubation time on the activity recovery of the enzymes during coimmobilization was examined, and the results are shown in Figure 3d. As it can be seen, the activity recovery of both enzymes increased with increasing incubation time demonstrating a maximum activity recovery after $5 \mathrm{~h}$ of incubation (bgl: $85 \%$ and CalA: $66 \%$ ). Lower time of incubation might not be sufficient for the attachment of enzymes onto MNPs. However, at extended incubation times, a decline in activity recoveries was observed in a similar manner as previously described [14,25], probably due to rigidification of enzymes that probably affects their configuration, thus leading to abolish enzyme activity.

Based on the experimental data mentioned above, the optimized preparation conditions for the bi-enzymatic magnetic nanobiocatalyst were: glutaraldehyde concentration, $10 \% v / v$; mass ratio of CS-MNPs to enzyme content, 1:8; mass ratio of bgl to CalA, 1:3 and incubation time, $5 \mathrm{~h}$. Under these conditions, the maximum activity recoveries for both bgl and CalA were $92.3 \%$ and $79.0 \%$, respectively.

\subsection{Characterization of the Bio-Nanoconjugates}

In order to confirm the successful binding of the enzymes on the CS-MNPs, as well as to investigate any structural changes on the nanomaterial's surface after the anchoring of the enzymes or possible interactions of the enzymes with the CS-MNPs, we applied several spectroscopic techniques, such as Fourier-transform infrared spectroscopy (FTIR), fluorescence spectroscopy and circular dichroism spectroscopy (CD).

\subsubsection{Fourier-Transform Infrared Spectroscopy (FTIR)}

The successful anchoring of bgl and CalA on the CS-MNPs was first confirmed by FTIR spectroscopy. Figure 4 illustrates the FTIR spectra of the CS-MNPs and the co-immobilized form of bgl and CalA. As it can be seen, the bands observed around 590 and $3400 \mathrm{~cm}^{-1}$ can be assigned to Fe-O deformation and $\mathrm{O}-\mathrm{H}$ stretching vibration of water molecules absorbed on the samples. The peak at $1083 \mathrm{~cm}^{-1}$, present in both spectra, can be attributed to the C-O stretching vibration of glycosidic bonds [13], while the peak at $1640 \mathrm{~cm}^{-1}$ is characteristic of the $-\mathrm{NH}_{2}$ bending vibration. Regarding the spectra of $\mathrm{Fe}_{3} \mathrm{O}_{4}$-chitosanbgl-CalA, two absorption bands of a typical protein spectrum are observed. The first absorption around $1649 \mathrm{~cm}^{-1}$ is associated with the Amide I band, which corresponds to 
the $\mathrm{C}=\mathrm{O}$ stretching vibrations of amide groups and $\mathrm{C}=\mathrm{N}$ of imine groups and is directly related to the backbone conformation of the protein [25]. For this reason, an increase in the absorption around $1640-1649 \mathrm{~cm}^{-1}$ in the $\mathrm{Fe}_{3} \mathrm{O}_{4}$-chitosan-bgl-CalA spectrum is observed. The second absorption around $1542 \mathrm{~cm}^{-1}$ is associated with the Amide II band of the proteins, which can be referred to $\mathrm{C}-\mathrm{N}$ stretching and $\mathrm{N}-\mathrm{H}$ bending vibration of the amide bond. These bands suggest the crosslink between chitosan and the two enzymes and thus their successful immobilization on CS-MNPs [25].

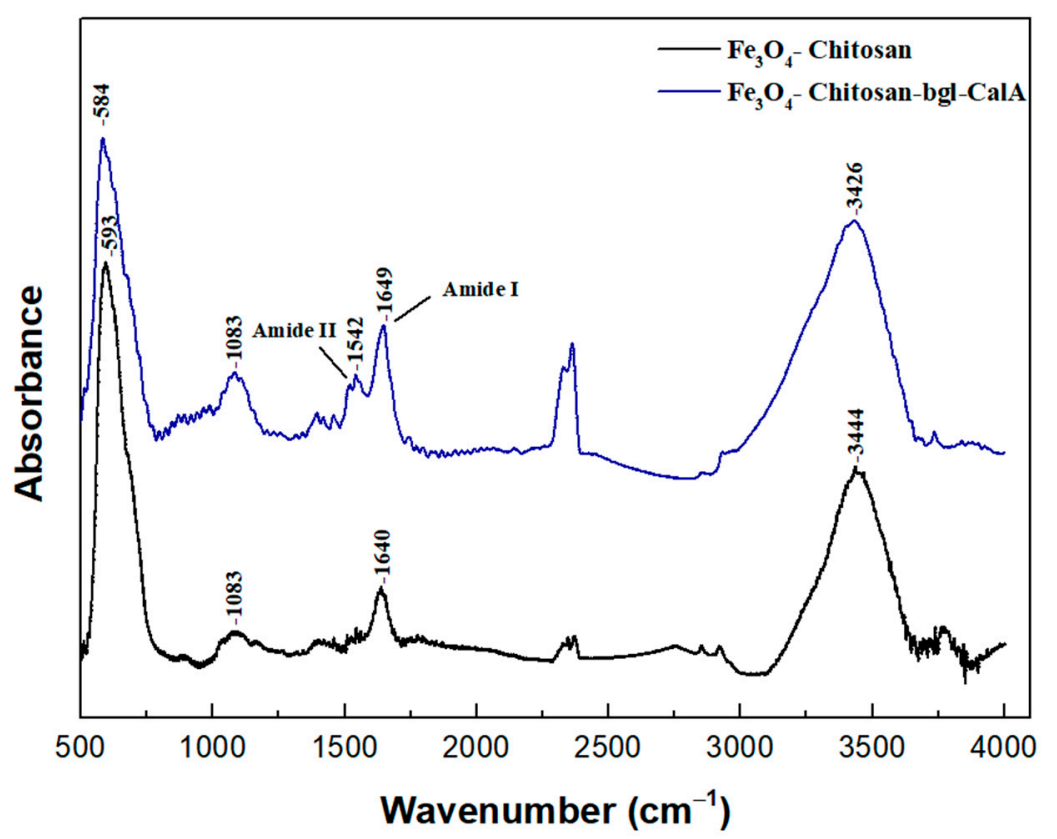

Figure 4. FTIR spectra of $\mathrm{Fe}_{3} \mathrm{O}_{4}$ chitosan and $\mathrm{Fe}_{3} \mathrm{O}_{4}$ chitosan-bgl-CalA nanoparticles, depicting their distinct peaks.

\subsubsection{Circular Dichroism Spectroscopy (CD)}

In order to investigate the conformational changes of bgl and CalA upon interaction with CS-MNPs, circular dichroism spectroscopy was applied. As it can be seen in Table 1, the interaction of both enzymes with CS-MNPs induces conformational changes that are associated with a slight decrease in the $\alpha$-helical content followed by an equal increase in the $\beta$-sheet content. The increase in $\beta$-sheet content could be attributed to the hydrophobic interactions between the enzymes and the CS-MNPs [30], while a loss in the $\alpha$-helical content has been associated with enzyme inactivation [31]. A slight decrease in the $\alpha$-helical content has been recently reported for a recombinant Bacillus subtilis lipase immobilized on magnetic nanoparticles [32]. The changes in the secondary structure of CalA in the presence of various carbon-based nanomaterials [30], as well as for the immobilized lipase from Thermomyces lanuginosus on multiwalled carbon nanotubes [33], also reveal a decrease in the $\alpha$-helical content followed by the increase in the $\beta$-sheet content. However, another study reported that the interaction of lipase B from Pseudozyma antarctica with magnetic porous carbon nanomaterials [34] resulted in a slight increase in the $\alpha$-helical content followed by a decrease in the $\beta$-sheet content, indicating that different kinds of nanomaterials can induce different conformational changes on protein structure.

A recently reported study highlighted the immobilization of bgl using Eudragit L100 (polyacrylic resin) as a carrier. Circular dichroism studies revealed that the proportion of $\alpha$-helix and turning angle decreased after immobilization while $\beta$-sheet and randomness increased [35], which is in good accordance with our results. The increase in $\beta$-sheet content can be correlated with a more rigid structure which subsequently results in enhanced stability that is also confirmed by the stability studies of immobilized bgl on CS-MNPs. 
Table 1. Estimation (\%) of the secondary structure elements by CD spectra analysis of bgl and CalA in aqueous solutions both in the absence and in the presence of $1.5 \mu \mathrm{g} \mathrm{mL}{ }^{-1}$ CS-MNPs.

\begin{tabular}{ccccc}
\hline Sample & & $\boldsymbol{\alpha}$-Helix & $\boldsymbol{\beta}$-Sheet & Other \\
\hline \multirow{2}{*}{ bgl } & Buffer & 28 & 19 & 53 \\
& CS-MNPs & 25 & 23 & 52 \\
\hline \multirow{2}{*}{ CalA } & Buffer & 32 & 17 & 51 \\
& CS-MNPs & 31 & 22 & 47 \\
\hline
\end{tabular}

\subsubsection{Fluorescence Spectroscopy}

Fluorescence spectroscopy is a widely applied technique for the confirmation of the presence of enzymes on solid material [36-38]. The fluorescence emission spectra of free, individually immobilized and co-immobilized form of bgl and CalA were recorded in order to confirm the successful anchoring of the enzymes on the CS-MNPs. Excitation wavelength was set at $280 \mathrm{~nm}$, and the emission intensity was recorded in the range of $300-400 \mathrm{~nm}$. The maximum emission wavelength of the free, individually immobilized and co-immobilized form of both $\mathrm{bgl}$ and CalA was found at $320 \mathrm{~nm}$. The fluorescence spectra of CS-MNPs were also recorded at the same conditions, and no emission was observed in the range of 300-400 nm. As it can be seen in Figure 5, in all cases, the fluorescence spectra of bionanoconjugates reveal a maximum emission at $320 \mathrm{~nm}$, which indicates the presence of the enzymes and, therefore, their successful immobilization on the CS-MNPs.

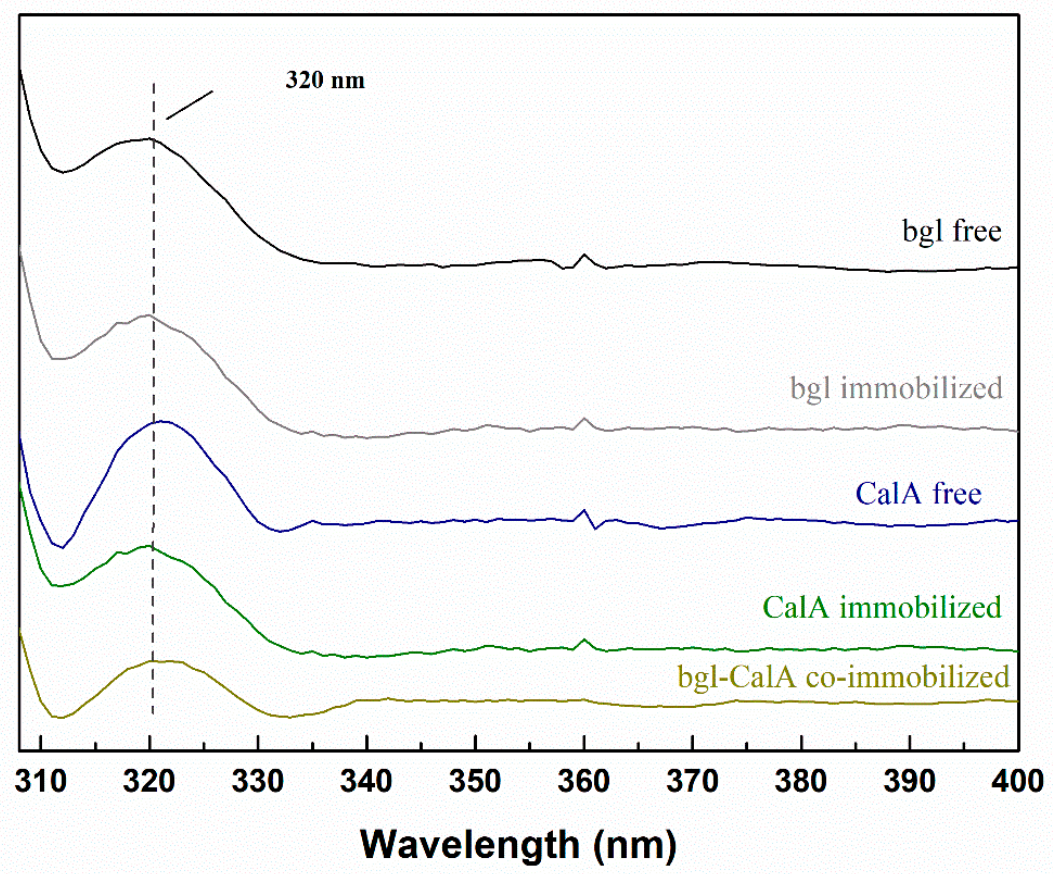

Figure 5. Fluorescence spectra of free, individually immobilized and co-immobilized form of CalA and bgl on CS-MNPs.

\subsection{Thermal Stability of the Bi-Enzymatic Nanobiocatalyst}

The thermal stability of enzymes consists of a crucial parameter especially when considering their industrial applications [39]. In order to examine the thermal stability of bgl and CalA in their free, individually immobilized or co-immobilized form, all samples were incubated at $60{ }^{\circ} \mathrm{C}$, in sodium phosphate buffer $50 \mathrm{mM}$, pH 7.0 for CalA and in citrate phosphate buffer $100 \mathrm{mM}, \mathrm{pH} 6.5$ for bgl. The individually immobilized form refers to the nanobiocatalyst consisting of either bgl or CalA covalently attached on the CS-MNPs, while the co-immobilized form refers to the hybrid nanobiocatalyst consisting of both bgl and CalA covalently attached onto the surface of the CS-MNPs. Measurements 
of the residual activity were taken at standard time intervals, as shown in Figure 6, in order to determine the half-life time of the enzymes, namely the time required for the enzyme to lose $50 \%$ of its initial activity. Table 2 demonstrates that the half-life time of CalA both in individually immobilized and co-immobilized form is significantly enhanced by about 6.6 and 5.6 times, respectively. Similar results highlighting an enhancement in thermal stability have been recently reported for the immobilization of CalA onto chitosan-coated magnetic nanoparticles [13]. In case of bgl used in this work, a well-known highly thermostable $\beta$-glucosidase [40], no significant decline in the residual activity was observed for temperatures in the range of $60-90{ }^{\circ} \mathrm{C}$ after $24 \mathrm{~h}$ of incubation for all forms (free, individually immobilized and co-immobilized) studied. Similar results have been reported for the immobilization of bgl from Thermotoga maritima on porous carbon cuboids nanoparticles [9] or for the co-immobilization of bgl on amino-functionalized magnetic nanoparticles [26]. These results suggest that chitosan-coated magnetic nanoparticles could be an ideal support for multienzyme immobilization leading to nanobiocatalysts with improved thermostability against denaturation at high temperatures compared to their native forms.

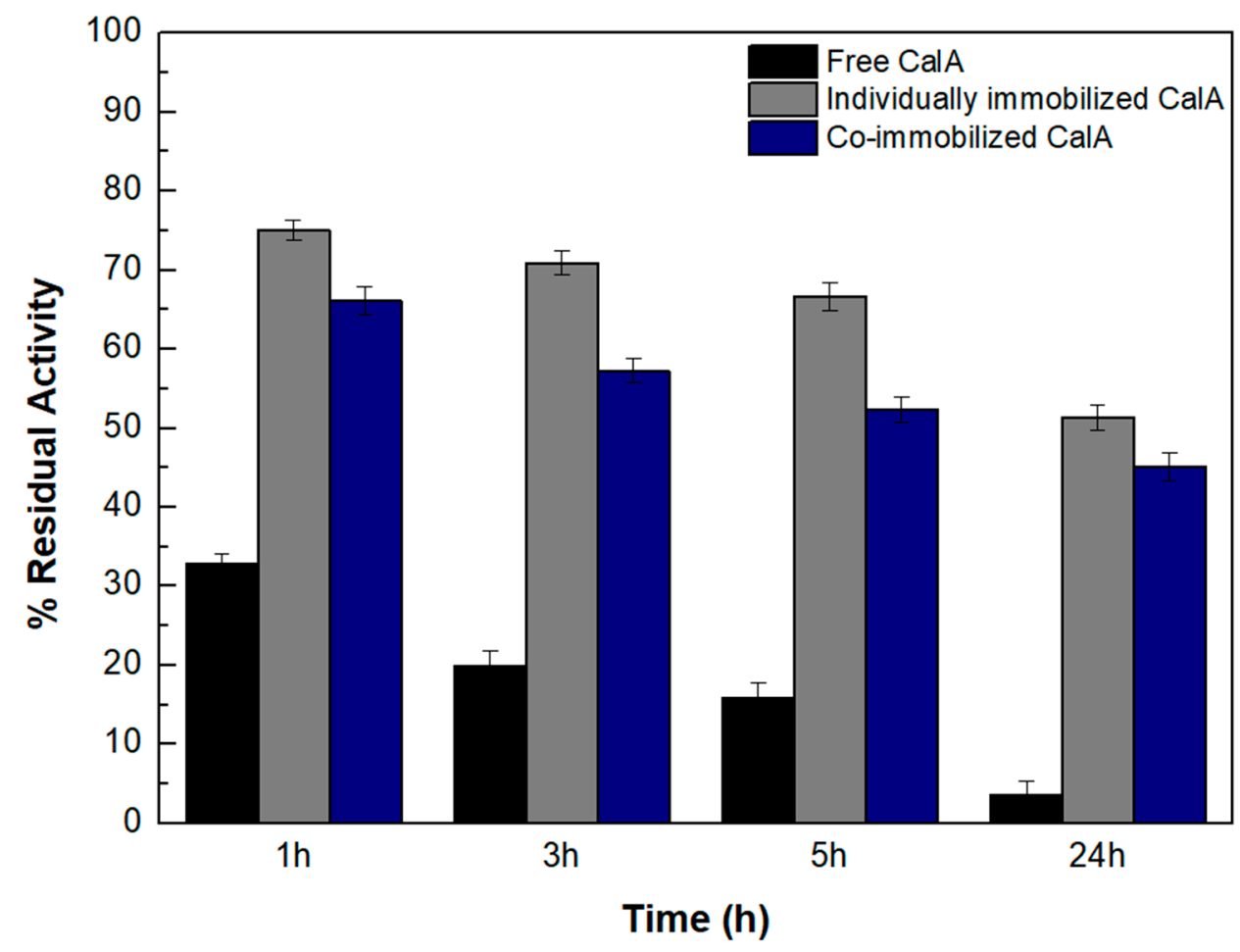

Figure 6. Stability of the free, individually immobilized and co-immobilized form of CalA at $60{ }^{\circ} \mathrm{C}$, in sodium phosphate buffer $50 \mathrm{mM}$, pH 7.0.

Table 2. Half-life times (h) at $60^{\circ} \mathrm{C}$ for CalA in free, individually immobilized and co-immobilized form (the standard deviation was less than $5 \%$ in all cases).

\begin{tabular}{cc}
\hline Sample & Half-Life Time (h) \\
\hline Free CalA & 7.8 \\
\hline Co-immobilized CalA & 44.2 \\
\hline Individually immobilized CalA & 51.8 \\
\hline
\end{tabular}

\subsection{Kinetic Studies of Free, Individually Immobilized and Co-Immobilized Biocatalysts}

In order to gain deeper insight into the affinity of each form of the two enzymes to their respective substrates, we evaluated the intrinsic (for the free form of the enzymes) 
and apparent (for the individually immobilized and co-immobilized forms of the enzymes) Michaelis constants [41]. Specifically, the determination of the enzyme kinetic constants $\left(\mathrm{K}_{\mathrm{m}}\right.$ and $\mathrm{V}_{\max }$ ) of the free, individually immobilized or co-immobilized form of bgl and CalA were calculated by the nonlinear regression fitting of the initial reaction rates, with respect to varying pNPG and pNPB concentrations, respectively. As shown in Tables 3 and 4, the apparent $K_{m}$ values of either individually or co-immobilized form of enzymes were higher than that of their native forms in all the cases, while the apparent $V_{\max }$ values decreased after immobilization and co-immobilization. The increase in $\mathrm{K}_{\mathrm{m}}$ values followed by a decrease in $V_{\max }$ values is usually observed after immobilization. The increase in $\mathrm{K}_{\mathrm{m}}$ values indicates that the affinity of enzymes toward their substrate declines after immobilization that could be probably due to conformational changes that consecutively reduce/restrict the diffusion of the respective substrates to the active site of the enzymes, indicating lower enzymatic reaction rates. Similar results have been observed for the immobilization of $\beta$ glucosidase from Thermotoga maritima on chitin-functionalized magnetic nanoparticles [42] and for the co-immobilization of alcalase and trypsin on $\mathrm{Fe}_{3} \mathrm{O}_{4}$ magnetic nanoparticles coated with chitosan-sodium tripolyphosphate [14].

Table 3. Intrinsic and apparent kinetic constants of free, individually immobilized and coimmobilized form of bgl at $60{ }^{\circ} \mathrm{C}$ (the standard deviation was less than $5 \%$ in all cases).

\begin{tabular}{ccc}
\hline Forms & $\mathbf{K}_{\mathbf{m}}(\mathbf{m M})$ & $\mathbf{V}_{\max }(\mu \mathbf{m o l} / \mathbf{m i n})$ \\
\hline Free bgl & 0.72 & 9.27 \\
\hline Co-immobilized bgl & 0.85 & 5.60 \\
\hline Individually immobilized bgl & 1.20 & 7.64 \\
\hline
\end{tabular}

Table 4. Intrinsic and apparent kinetic constants of free, individually immobilized and coimmobilized form of CalA at $60^{\circ} \mathrm{C}$ (the standard deviation was less than $5 \%$ in all cases).

\begin{tabular}{ccc}
\hline Forms & $\mathbf{K}_{\mathbf{m}}(\mathbf{m M})$ & $\mathbf{V}_{\mathbf{m a x}}(\mathbf{m o l} / \mathbf{m i n})$ \\
\hline Free CalA & 0.07 & 0.07 \\
\hline Co-immobilized CalA & 0.17 & 0.04 \\
\hline Individually immobilized CalA & 0.22 & 0.05 \\
\hline
\end{tabular}

2.6. Application of the Bi-Enzymatic Nanobiocatalyst to the Bioconversion of Oleuropein to Hydroxytyrosol

The developed bi-enzymatic nanobiocatalytic system was applied to the two-step bioconversion of oleuropein to hydroxytyrosol. Specifically, as illustrated in Figure 1, in the first step, $\beta$-glucosidase cleavages the glucosidic bond of oleuropein, producing oleuropein algycon and glucose. In the following step, a lipase such as CalA can catalyze the hydrolysis of oleuropein aglycone to elenolic acid and hydroxytyrosol. A variety of different lipases were tested for their ability to hydrolyze the OLE ester bond where CalA presented the highest conversion yield (see Supplementary File, Table S1). We applied four different reaction systems and evaluated their reaction rates, the \% conversion yield of oleuropein (determined through HPLC analysis) and the amount of hydroxytyrosol $\left(\mathrm{mg} \mathrm{mL}^{-1}\right.$ ) produced as shown in Table 5. In the case of individually immobilized bgl or CalA, the conversion yield of oleuropein presented refers to either the cleavage of the glucosidic bond of oleuropein or to the hydrolysis of the OLE ester bond, respectively. In the case of co-immobilized biocatalyst or the simultaneous use of the two individually immobilized biocatalysts in the reaction mixture, the oleuropein conversion yield could be attributed to their synergistic action. High-pressure liquid chromatography (HPLC) was employed for the identification and quantification of oleuropein and hydroxytyrosol, as well as for the reaction progress monitoring. Nuclear magnetic resonance (NMR) was employed for the characterization of the products of the enzymatic hydrolysis of oleuropein, 
such as hydroxytyrosol, elenolic acid and glucose (see Supplementary File, Figure S2). Figure 7 illustrates the reaction progress of the enzymatic hydrolysis of oleuropein catalyzed by the bi-enzymatic magnetic complex. Table 5 depicts the initial reaction rates of individually immobilized bgl and CalA and co-immobilized bgl-CalA system for the hydrolysis of oleuropein and percentage conversion yield of oleuropein. As it can be seen in Table 5, individually immobilized biocatalysts or their combination are characterized by lower conversion rates than the co-immobilized magnetic nanobiocatalyst. Similar results highlighting the superior catalytic activity of co-immobilized biocatalysts compared to the individually immobilized ones have been reported by Sojitra and co-workers [28]. In that work, a magnetic tri-enzyme nanobiocatalyst for fruit juice clarification was developed, suggesting that co-immobilization enables substrate channeling, thus leading to higher reaction yields than the individually immobilized enzymes. Moreover, it should be noted than even though both individually immobilized bgl and co-immobilized complex presented a $100 \%$ conversion yield of oleuropein, the yield for hydroxytyrosol was significantly lower in the case of individually immobilized bgl, suggesting that the combination of the two enzymes is essential for achieving high hydroxytyrosol yields. Similar results, suggesting a synergistic action of $\mathrm{bgl}$ and CalA have also been observed when the enzymes were used in their free form (see Supplementary File, Table S2).

Table 5. Initial reaction rates of individually immobilized bgl and CalA and co-immobilized bgl-CalA for the hydrolysis of oleuropein, percentage conversion yield of oleuropein and amount $\left(\mathrm{mg} \mathrm{mL}^{-1}\right)$ of hydroxytyrosol produced after $24 \mathrm{~h}$ of incubation in citrate phosphate buffer $100 \mathrm{mM}$, pH 6.5 at $60{ }^{\circ} \mathrm{C}$ (the standard deviation was less than $5 \%$ in all cases).

\begin{tabular}{|c|c|c|c|}
\hline Sample & $\begin{array}{c}\text { Initial Reaction Rate } \\
\text { (mM h }{ }^{-1} \mathrm{mg}^{-1} \text { Nanobiocatalyst) }\end{array}$ & $\begin{array}{l}\% \text { Conversion Yield } \\
\text { of Oleuropein }\end{array}$ & $\begin{array}{l}\text { Hydroxytyrosol } \\
\left(\mathrm{mg} \mathrm{mL}^{-1}\right)\end{array}$ \\
\hline Individually immobilized bgl & 0.038 & 100 & 0.150 \\
\hline Individually immobilized CalA & 0.021 & 40 & 0.880 \\
\hline Individually immobilized bgl and CalA & 0.032 & 90 & 1.210 \\
\hline Co-Immobilized bgl-CalA & 0.046 & 100 & 2.000 \\
\hline
\end{tabular}

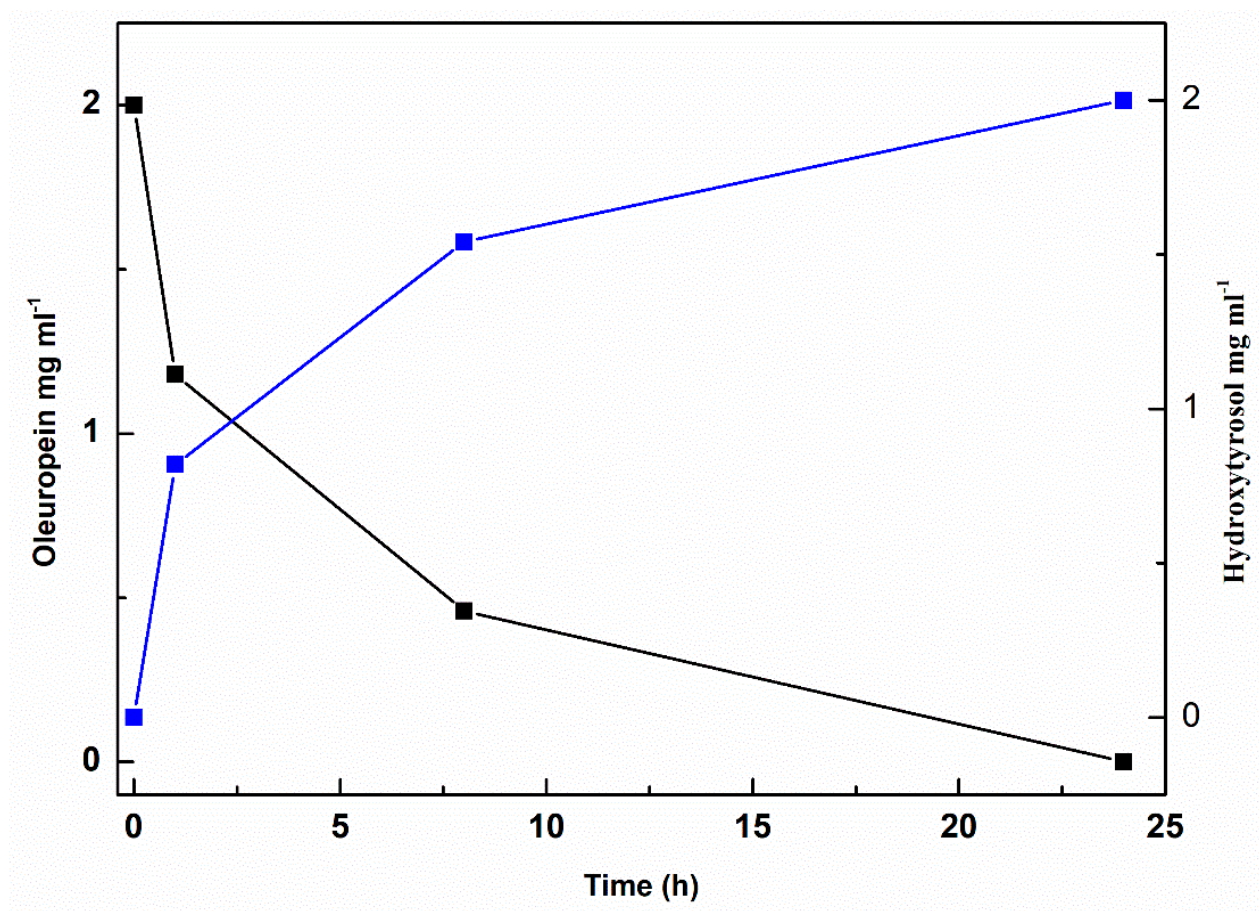

Figure 7. Reaction progress of the hydrolysis of oleuropein by the bi-enzymatic nanobiocatalyst $\left(1 \mathrm{mg} \mathrm{mL}^{-1}\right)$ at different time intervals and the formation of hydroxytyrosol (the standard deviation was less than $5 \%$ in all cases). 


\subsection{Reusability of the Bi-Enzymatic Nanobiocatalyst}

Recycling of multienzymatic nanobiocatalysts is vital in terms of economic viability especially when considering large-scale biocatalytic processes. In the present study, the operational stability of the bi-enzymatic nanobiocatalyst was evaluated for 10 successive reaction cycles of the bioconversion of oleuropein in a batch mode. Each reaction cycle was carried out in citrate phosphate buffer $100 \mathrm{mM} \mathrm{pH} 6.5$ at $60^{\circ} \mathrm{C}$ for $24 \mathrm{~h}$. After each cycle, the nanobiocatalyst was separated through magnetization, washed twice with buffer to remove substrate and product remains and then added to fresh oleuropein solution in order to start a new reaction cycle. Figure 8 illustrates the residual activity of the nanobiocatalyst after each cycle. The remaining hydrolytic activity of the magnetic coimmobilized complex is up to $50 \%$ after 10 catalytic cycles, which equals about $240 \mathrm{~h}$ of constant operation. Similar results have been reported for immobilized CalA onto chitosancoated magnetic nanoparticles, where the biocatalyst gave half of the initial conversion after 7 reaction cycles [13] or for immobilized bgl from Thermotoga maritima on chitinfunctionalized magnetic nanoparticles where the nanobiocatalyst presented about $66 \%$ of residual activity after 10 reaction cycles [42]. In the case of co-immobilized enzymes, the conservation up to $75 \%$ of residual activity after eight consecutive cycles of a tri-enzyme magnetic nanobiocatalyst [28] and the retention of up to $50 \%$ after 5 reaction cycles at $50{ }^{\circ} \mathrm{C}$ for a four-enzyme magnetic co-immobilized complex have been reported [26]. Any loss in activity could be attributed to conformational changes on the immobilized enzymes [9] or mechanical damage of the biocatalyst during the recycling procedure [26]. Our results are in good agreement with previously reported studies indicating that multienzyme immobilization on magnetic nanosupports can lead to stable biocatalysts that can be efficiently applied for bioconversions of biotechnological interest, such as the synthesis of hydroxytyrosol from oleuropein.

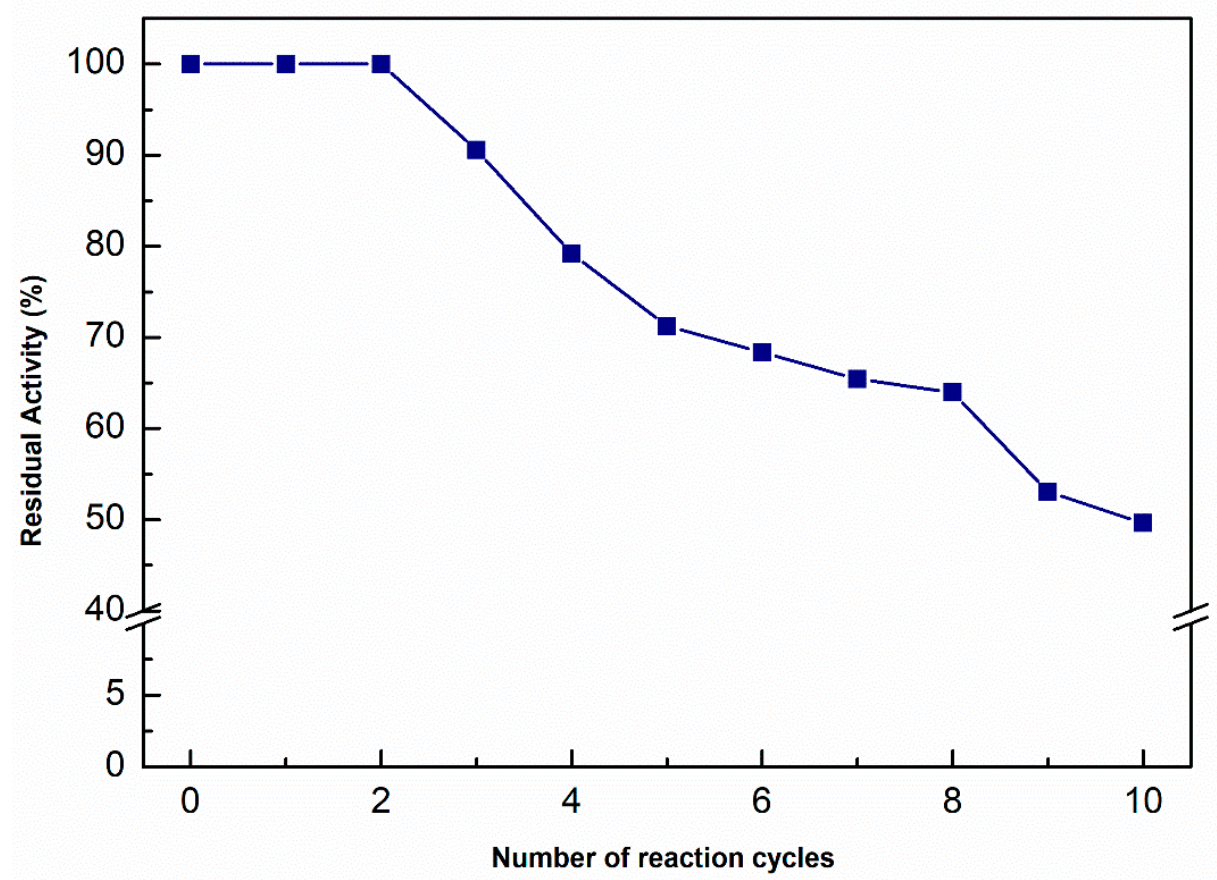

Figure 8. Reusability studies of the bi-enzymatic magnetic complex comprising bgl and CalA for 10 consecutive cycles. The biotransformation of oleuropein to hydroxytyrosol was carried in citrate phosphate buffer $100 \mathrm{mM} \mathrm{pH} 6.5$ at $60{ }^{\circ} \mathrm{C}$ for $24 \mathrm{~h}$ (the standard deviation was less than $5 \%$ in all cases). 


\section{Materials and Methods}

\subsection{Materials}

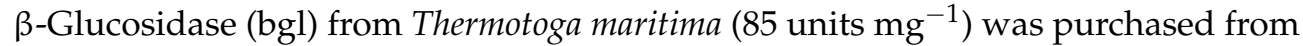
Megazyme (Chicago, IL, USA) and was used with no further purification. Novozyme 735 (lipase A from Pseudozyma (Candida) antarctica, CalA) and Lipase B from Pseudozyma (Candida) antarctica (CaLB) were generously provided by Novozymes (Bagsværd, Denmark). Lipase from Thermomyces lanuginosus (Lipozyme, TLL, 100 L) was generously provided from Novozymes. Lipase from Aspergillus oryzae (solution, $\geq 100,000 \mathrm{U} / \mathrm{g}$ ), lipase from Mucor miehei, (lyophilized powder, $\geq 4000$ units/mg solid) and lipase from Candida antarctica (lyophilized powder, $0.3 \mathrm{U} / \mathrm{mg}$ ) were purchased from Sigma-Aldrich (St. Louis, MO, USA). Glutaraldehyde solution ( $25 \% v / v$ in $\left.\mathrm{H}_{2} \mathrm{O}\right)$, 4-nitrophenyl $\beta$ - $D$-galactoside, $(p$-NPG, $\geq 98 \%$ ), $p$-nitrophenyl butyrate ( $p$-NPB), $p$-nitrophenol $(p$-NP), iron (II,III) oxide nanopowder, 50-100 nm particle size (SEM), 97\% trace metals basis, sodium tripolyphosphate (TPP) and chitosan from crab shells (low viscosity) were all purchased from Sigma-Aldrich (St. Louis, MO, USA). Oleuropein was purchased from Biosynth Carbosynth (Sankt Gallen, Switzerland). All the other chemicals and reagents were of analytical grade and procured from reliable sources. Milli-Q water was used for the preparation of all the buffers and solutions.

\subsection{Methods}

All experiments were performed by triplicate, and the values are given as mean values and experimental errors.

3.2.1. Functionalization of Iron Oxide Magnetic Nanoparticles $\left(\mathrm{Fe}_{3} \mathrm{O}_{4}\right)$ with Chitosan (CS-MNPs)

In a typical synthesis protocol, $8 \mathrm{mg}$ of iron oxide magnetic nanoparticles $\left(\mathrm{Fe}_{3} \mathrm{O}_{4}\right)$ was dispersed in $0.96 \mathrm{~mL}$ CS solution $(0.2 \% w / v)$. Figure 9 schematically represents the functionalization of MNPs with chitosan. For the preparation of the chitosan solution $0.2 \mathrm{~g}$ of CS powder was dissolved in $100 \mathrm{~mL}$ of $1 \% v / v$ acetic acid. Then, $0.32 \mathrm{~mL}$ of sodium tripolyphosphate solution $\left(1.5 \mathrm{mg} \mathrm{mL}^{-1}\right)$ was added dropwise to the dispersion and mixed under constant magnet stirring $(1000 \mathrm{rpm})$ for $0.5 \mathrm{~h}$ at $25^{\circ} \mathrm{C}$. CS-MNPs were subsequently gathered through magnetization (see Supplementary File, Figure S3) and washed thrice with water and ethanol. Finally, the CS-MNPs were dried at $45^{\circ} \mathrm{C}$ overnight for further use.
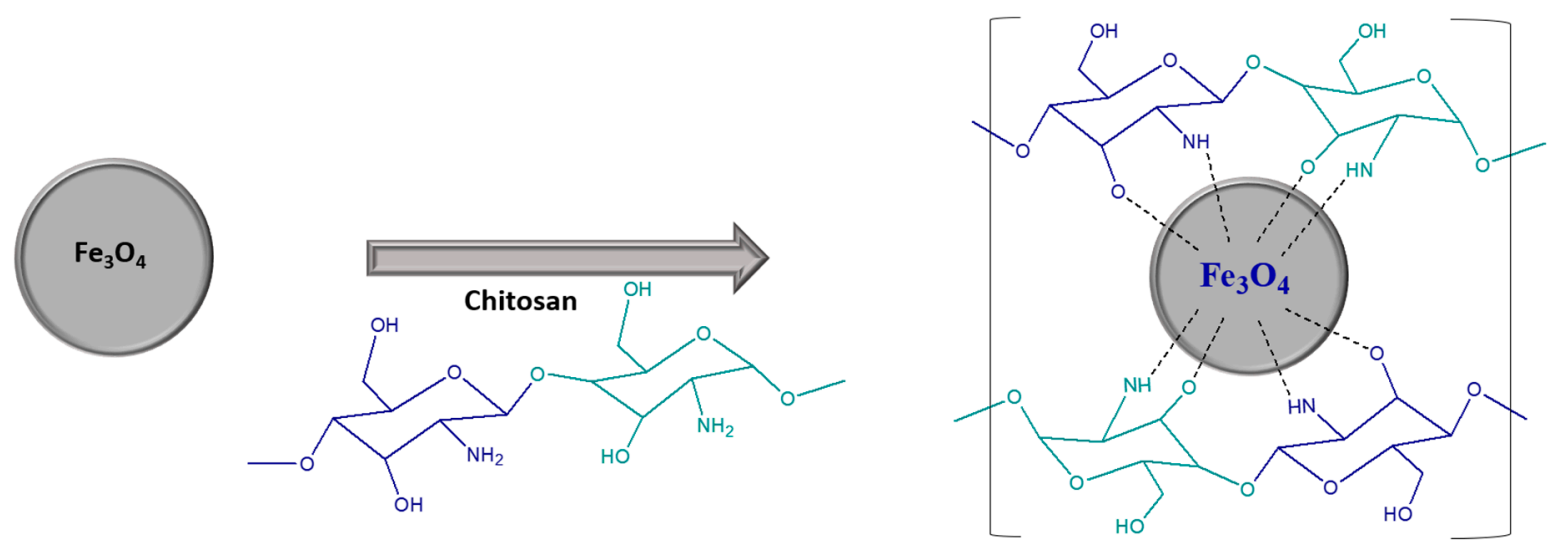

Figure 9. Schematic representation of the functionalization of MNPs with chitosan.

\subsubsection{Characterization of the Chitosan-Functionalized Magnetic Nanoparticles $\mathrm{XRD}$}

The powder X-ray diffraction patterns were collected on a D8 Advanced Bruker diffractometer (Bruker, Billerica, MA, USA) using $\mathrm{CuK} \alpha(40 \mathrm{kV}, 40 \mathrm{~mA})$ radiation and a 


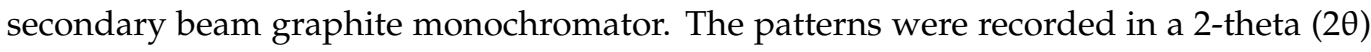
range from 2 to $80^{\circ}$, in steps of $0.02^{\circ}$ and counting time $2 \mathrm{~s}$ per step.

AFM

Atomic force microscopy (AFM) images were obtained in tapping mode with a Bruker Multimode 3D Nanoscope (Ted Pella Inc., Redding, CA, USA) using a microfabricated silicon cantilever type TAP-300G, with a tip radius of $<10 \mathrm{~nm}$ and a force constant of approximately $20-75 \mathrm{~N} \mathrm{~m}^{-1}$.

\subsubsection{Preparation of Bi-Enzymatic Magnetic Nanobiocatalyst}

CalA and bgl were covalently attached onto the surface of CS-MNPs employing glutaraldehyde as crosslinker, which links the free $\mathrm{NH}_{2}$ groups present in chitosan with the free amino groups of the enzymes. In a typical protocol, $24 \mathrm{mg}$ of nanomaterial was dispersed in sodium phosphate buffer $(10 \mathrm{~mL}, 100 \mathrm{mM}, \mathrm{pH}$ 6.5) in the presence of $0.11 \mathrm{~mL}$ Tween-20 $(1 \% v / v)$, and the mixture was incubated in an ultrasonic bath for $30 \mathrm{~min}$. After $30 \mathrm{~min}$, the crosslinker glutaraldehyde $(10 \% \mathrm{v} / \mathrm{v})$ was added, and the mixture was allowed to shake for $30 \mathrm{~min}$ under agitation at room temperature $(30 \pm 2)$. Thorough centrifugation followed the removing of the glutaraldehyde excess. The activated nanoparticles were redispersed in sodium phosphate buffer $(10 \mathrm{~mL}, 100 \mathrm{mM}, \mathrm{pH}$ 6.5), and the enzyme cocktail (total protein content of $3 \mathrm{mg}$ ) containing bgl and CalA (in a typical mass ratio of 1:3) was added into the solution. Then, the mixture was incubated for $5 \mathrm{~h}$ with constant shaking at $150 \mathrm{rpm}$. After crosslinking, the co-immobilized enzymes were separated with magnet, washed thrice with sodium phosphate buffer $\left(100 \mathrm{mM}, \mathrm{pH}\right.$ 6.5) and stored at $4{ }^{\circ} \mathrm{C}$. The prepared nanobiocatalyst was used as magnetic bi-enzymatic nanobiocatalyst. Several parameters of the co-immobilization procedure, such as the glutaraldehyde concentration ( $5 \%, 10 \%, 15 \%$ and $20 \%)$, the incubation time ( $1 \mathrm{~h}, 3 \mathrm{~h}, 5 \mathrm{~h}$ and $20 \mathrm{~h})$, the bgl to CalA mass ratio (4:1, 3:1, 2:1, 1:1, 1:2, 1:3 and 1:4) and the total enzyme mass to CS-MNPs ratio $(0.5: 1,1: 1,1: 2,1: 4,1: 6$ and 1:8) were examined by one factor at a time in order to attain the maximum activity recoveries of the two enzymes. The activities of enzymes were expressed as activity recovery (\%), which is determined as the percent activity of each immobilized enzyme ( $\mathrm{U}$ ) divided by the total initial activity of each enzyme. CalA and bgl were also immobilized separately (individually) onto CS-MNPs using glutaraldehyde as the crosslinker. The immobilization percentage was determined by the Bradford assay [43] through the difference of the protein concentration in the supernatant before and after the immobilization. All experiments were carried out in triplicate.

\subsubsection{Characterization of the Bi-Enzymatic Magnetic Nanobiocatalyst}

Fourier-Transform Infrared Spectroscopy (FTIR)

The confirmation of the characteristic functional peaks of chitosan-functionalized magnetic nanoparticles and bi-enzymatic nanobiocatalyst, was performed through a FTIR8400 infrared spectrometer (Shimadzu, Tokyo, Japan) equipped with a deuterated triglycine sulfate (DTGS) detector. All spectra were recorded within the $400-4000 \mathrm{~cm}^{-1}$ range and on average of 32 scans.

\section{Circular Dichroism Spectroscopy (CD)}

Circular dichroism measurements were performed on a Jasco J-1500 spectropolarimeter (Tokyo, Japan), equipped with a Peltier system for temperature control. A quartz cell of $10 \mathrm{~mm}$ path length was used. All spectra were recorded at $25^{\circ} \mathrm{C}$, with a $2 \mathrm{~nm}$ bandwidth of the incident light and a scan speed of $50 \mathrm{~nm} \mathrm{~min}{ }^{-1}$. The baseline was recorded and subtracted from the protein spectrum for every sample scanned. The protein concentration was $6 \mu \mathrm{g} \mathrm{mL} \mathrm{L}^{-1}$ for bgl in citrate phosphate buffer $(5 \mathrm{mM}, \mathrm{pH}$ 6.5) and $5 \mu \mathrm{g} \mathrm{mL}{ }^{-1}$ for CalA in phosphate buffer ( $5 \mathrm{mM}, \mathrm{pH} 7.5$ ), according to the Beer-Lambert equation. CS-MNPs were added at a final concentration of $1.5 \mu \mathrm{g} \mathrm{mL}-1$ to minimize any optical phenomena that lowered the signal-to-noise ratio. At least two scans were collected 
and averaged. Data obtained from CD were analyzed using the DICHROWEB website: http:/ / www.dichroweb.cryst.bbk.ac (Accessed on: 19 May 2020) [44,45].

Fluorescence Spectroscopy

All of the fluorescence measurements were taken at a luminescence spectrofluorometer Jasco-8300 (Tokyo, Japan) by using a solid sample holder. Individually immobilized and co-immobilized enzymes were used in aqueous solutions at concentrations of $1 \mathrm{mg} \mathrm{mL}^{-1}$, while free bgl and CalA at concentrations of $0.45 \mu \mathrm{g} \mathrm{mL}^{-1}$ and $1 \mathrm{mg} \mathrm{mL}^{-1}$, respectively. Samples were deposited onto silicon wafers (P/Bor, single-side polished) from aqueous solutions by drop casting. The fluorescence emission spectra were recorded from 300 to $400 \mathrm{~nm}$ after exciting at $280 \mathrm{~nm}$, with a scan speed of $100 \mathrm{~nm} \mathrm{~min}{ }^{-1}$ at $25^{\circ} \mathrm{C}$. Slit widths with a nominal band pass of $5 \mathrm{~nm}$ were used for both excitation and emission ray.

\subsubsection{Enzyme Assays}

The enzymatic assays of the free, individually immobilized and co-immobilized $\beta$-glucosidase were performed on a UV-Vis spectrophotometer equipped with a Peltier temperature controller (Shimadzu, Tokyo, Japan). The activity of bgl was determined by using $\mathrm{p}-\mathrm{NPG}$ as a substrate. Under optimum conditions, $\beta$-glucosidase hydrolyzes p-NPG into p-NP (coloured product) and glucose. For the activity assay, $0.12 \mu \mathrm{g} \mathrm{mL}-1$ of free enzyme solution (or equivalent amount of individually immobilized and co-immobilized bgl) was mixed with $2.0 \mathrm{mM}$ p-NPG in $100 \mathrm{mM}$ citrate phosphate buffer, pH 6.5 at $60{ }^{\circ} \mathrm{C}$. The reaction was followed by measuring the increase in absorbance of p-NP at $410 \mathrm{~nm}$ spectrophotometrically. Absorption values are taken every minute for a total of five minutes and were converted to $\mathrm{p}-\mathrm{NP}$ concentration using the molar extinction coefficient of $\mathrm{p}-\mathrm{NP}$ at $410 \mathrm{~nm}$ [46]. Enzymatic activity was estimated as the amount ( $\mu$ moles) of p-NP transformed per minute.

The enzymatic assays of the free, individually immobilized and co-immobilized CalA were performed on a UV-Vis spectrophotometer equipped with a Peltier temperature controller (Shimadzu, Tokyo, Japan). The activity of CalA was determined by the hydrolysis of p-NPB as substrate. The released p-NP was quantified spectrophotometrically at $348 \mathrm{~nm}$. For the activity assay, $0.08 \mu \mathrm{g} / \mathrm{mL}$ of free enzyme solution (or equivalent amount of individually immobilized and co-immobilized CalA) was mixed with $0.5 \mathrm{mM}$ p-NPB in $50 \mathrm{mM}$ sodium phosphate buffer, $\mathrm{pH} 7.0$ at $25^{\circ} \mathrm{C}$. The reaction was followed by measuring the increase in absorbance of p-NP at $348 \mathrm{~nm}$ spectrophotometrically. Absorption values are taken every minute for a total of 10 minutes and were converted to p-NP concentration using the molar extinction coefficient of p-NP at $348 \mathrm{~nm}$ [13]. Enzymatic activity was estimated as the amount ( $\mu$ moles) of p-NP transformed per minute. The protein concentration was measured by the Bradford method, and bovine serum albumin was used as reference.

\subsubsection{Thermal Stability Studies}

Thermal stability studies of the free, individually immobilized and co-immobilized form of bgl and CalA were performed by incubating bgl in citrate phosphate buffer $100 \mathrm{mM}$, $\mathrm{pH} 6.5$ and CalA in $50 \mathrm{mM}$ sodium phosphate buffer, $\mathrm{pH} 7.0$ at $60^{\circ} \mathrm{C}$ for $24 \mathrm{~h}$. The hydrolytic activity of bgl and CalA was determined at different time intervals through the hydrolysis of either the p-NPG or p-NPB, respectively, as described above. All experiments were carried out in triplicate.

\subsubsection{Kinetic Studies of Free, Individually Immobilized and Co-Immobilized Biocatalysts}

Intrinsic and apparent kinetic parameters $\left(\mathrm{K}_{\mathrm{m}}, \mathrm{V}_{\mathrm{max}}\right)$ of the different forms of bgl and CalA (free, individually immobilized and co-immobilized) were estimated through the measurement of the initial reaction rates at varying concentrations of $\mathrm{p}-\mathrm{NPG}$ and $\mathrm{p}-\mathrm{NPB}$, respectively, at $60{ }^{\circ} \mathrm{C}$ as described above. The concentrations of p-NPG tested were: $0,0.05$, $0.1,0.15,0.25,0.5,1,2,5,10$ and $20 \mathrm{mM}$ and for $\mathrm{p}-\mathrm{NPB}$ the concentrations examined were: $0,0.025,0.05,0.075,0.1,0.125,0.25,0.5,0.75$ and $1 \mathrm{mM}$. The Michaelis-Menten constant 
$\left(\mathrm{K}_{\mathrm{m}}\right)$ and maximum velocity $\left(\mathrm{V}_{\max }\right)$ were calculated from nonlinear regression fitting of the initial reaction rates corresponding to different substrate concentrations by the EnzFitter (Biosoft) software.

3.2.8. Hydrolysis of Oleuropein to Hydroxytyrosol by the Bi-Enzymatic Nanobiocatalyst High-Performance Liquid Chromatography (HPLC) Analysis

The enzymatic hydrolysis of oleuropein was performed in citrate-phosphate buffer $100 \mathrm{mM}, \mathrm{pH}$ 6.5. In brief, $1 \mathrm{mg}$ of the magnetic nanobiocatalyst was dispersed in $2 \mathrm{mg} \mathrm{mL}^{-1}$ solution of oleuropein $(3.7 \mathrm{mM})$ in a final volume of $1 \mathrm{~mL}$, which was followed by $24 \mathrm{~h}$ incubation at $60{ }^{\circ} \mathrm{C}$ under agitation $(1200 \mathrm{rpm})$. The nanobiocatalyst $\left(1 \mathrm{mg} \mathrm{mL}^{-1}\right)$ was separated from the reaction mixture by using an external magnet, and the reaction mixture was eluted with methanol (1:1 ratio) and filtered with $0.45 \mathrm{~mm}$ filters. The identification and quantification of oleuropein and hydroxytyrosol were performed by high-performance liquid chromatography (HPLC) (Shimadzu, Tokyo, Japan) using a $\mu$ Bondapack C18 column, particle size $10 \mu \mathrm{m}$, length $300 \mathrm{~mm}$, diameter $3.9 \mathrm{~mm}$, and a diode array UV detector as described in our previous work [9]. The mobile phase consisted of acetonitrile (A) and $0.1 \%$ acetic acid in water (B). The elution conditions applied for solvent $\mathrm{B}$ were as follows: $0-30 \mathrm{~min} 80-50 \%, 30-35 \mathrm{~min} 50 \%$ and $35-40 \mathrm{~min} 80 \%$. The elution conditions were performed at $27{ }^{\circ} \mathrm{C}$ with a flow rate of $1 \mathrm{~mL} \mathrm{~min}^{-1}$, and the samples were detected at $280 \mathrm{~nm}$. The retention times of oleuropein and hydroxytyrosol were $20.16 \mathrm{~min}$ and $7.47 \mathrm{~min}$, respectively, while the retention time of the oleuropein aglycon products was in the range of 20-23 min. The quantification and characterization of oleuropein and hydroxytyrosol was based on standard compounds and calibration curves under the same conditions.

\subsubsection{Nuclear Magnetic Resonance (NMR) Analysis}

The characterization of the products hydroxytyrosol, elenolic acid and glucose in the crude reaction mixture of the enzymatic hydrolysis of oleuropein by the bi-enzymatic nanobiocatalytic system of co-immobilized bgl-CalA was performed through ${ }^{1} \mathrm{H}-\mathrm{NMR}$ analysis. The enzymatic hydrolysis of oleuropein was performed directly in $\mathrm{D}_{2} \mathrm{O}$ solution of citrate-phosphate buffer $100 \mathrm{mM}$, pH 6.5 in a final volume of $1 \mathrm{~mL}$. In brief, $1 \mathrm{mg}$ of the magnetic nanobiocatalyst was dispersed in $2 \mathrm{mg} \mathrm{mL}^{-1}$ solution of oleuropein $(3.7 \mathrm{mM})$ in a final volume of $1 \mathrm{~mL}$, which was followed by $24 \mathrm{~h}$ incubation at $60^{\circ} \mathrm{C}$ under shaking $(1200 \mathrm{rpm})$. The nanobiocatalyst was separated from the reaction mixture with the use of an external magnetic field, and the sample of the crude reaction mixture was transferred in an NMR tube ( $5 \mathrm{~mm})$. A Bruker $500 \mathrm{MHz}$ AV spectrometer, equipped with a broadband inverse probe (Bruker Biospin, Rheinstetten, Germany), was used to record the ${ }^{1} \mathrm{H}-\mathrm{NMR}$ spectra at $25{ }^{\circ} \mathrm{C}$, controlled by the software TopSpin 3.2. The ${ }^{1} \mathrm{H}-\mathrm{NMR}$ analysis of the standard compounds oleuropein, hydroxytyrosol and glucose was also performed in $\mathrm{D}_{2} \mathrm{O}$ solution of citrate-phosphate buffer $100 \mathrm{mM}, \mathrm{pH} 6.5$.

\subsubsection{Reusability Studies}

The reusability of the bi-enzymatic nanobiocatalyst was determined through the completion of consecutive operating cycles for the hydrolysis of $2 \mathrm{mg} \mathrm{mL}^{-1}$ oleuropein. Each reaction cycle was carried out for $24 \mathrm{~h}$ at $60^{\circ} \mathrm{C}$ under constant shaking (1200 rpm) in citrate-phosphate buffer solution $100 \mathrm{mM}, \mathrm{pH}$ 6.5. After each cycle, the nanobiocatalyst $\left(1 \mathrm{mg} \mathrm{mL}^{-1}\right.$ ) was separated from the reaction mixture with the use of a magnet and washed efficiently with citrate-phosphate buffer solution $100 \mathrm{mM}, \mathrm{pH} 6.5$, and then, it was resuspended in fresh substrate solution for the initiation of a new reaction cycle. The process was repeated for 10 successive cycles. The activity of each enzyme after each cycle was assessed by means of residual activity. The activity of the first cycle was considered to be $100 \%$.

\section{Conclusions}

In the present work, the simultaneous covalent co-immobilization of two hydrolytic enzymes, namely $\beta$-glycosidase from Thermotoga mariritima and Lipase A from Candida 
antarctica, for the development of a robust bi-enzymatic nanobiocatalytic system was reported. Chitosan-coated magnetic nanoparticles proved to be an ideal support for the anchoring of the two enzymes leading to high-recovery activities after co-immobilization. The developed nanobiocatalyst presented enhanced thermal stability at $60^{\circ} \mathrm{C}$ and exhibited high reaction yields during its successful use for the bioconversion of oleuropein to hydroxytyrosol. In addition, due to the magnetic core of the CS-MNPs, the nanobiocatalyst could be easily separated from the reaction mixture by applying an external magnetic field, facilitating its reuse in the bioconversion of oleuropein, thus retaining more than $50 \%$ of its initial activity after $240 \mathrm{~h}$ of constant operation. The numerous advantages of multienzyme co-immobilization such as shorter cycle times, elimination of reaction byproducts and intermediates or reduction of diffusion losses promote atom economy, high yield and efficiency of the total enzymatic process, endorsing that this method can provide an efficient way to design efficient multienzymatic nanoassemblies for a wide range of biocatalysts applications.

Supplementary Materials: The following are available online at https:/ /www.mdpi.com/article/10 $.3390 /$ catal11060749/s1, Figure S1: X-ray powder diffraction (XRPD) patterns of (a) $\mathrm{Fe}_{3} \mathrm{O}_{4}$ and (b) $\mathrm{Fe}_{3} \mathrm{O}_{4}$ chitosan nanoparticles; Table S1: Concentration of the released hydroxytyrosol through the hydrolysis of oleuropein from lipases of different origin (the standard deviation was less than $5 \%$ in all cases); Table S2: Concentration of the released hydroxytyrosol through the hydrolysis of oleuropein through different combinations of the enzymes bgl and CalA (the standard deviation was less than $5 \%$ in all cases); Figure S2: Superposition of ${ }^{1} \mathrm{H}-\mathrm{NMR}$ spectra of (a) glucose, (b) hydroxytyrosol, (c) oleuropein and (d) the reaction mixture of the enzymatic hydrolysis of oleuropein by the bi-enzymatic nanobiocatalytic system of co-immobilized bgl-CalA, in citrate-phosphate buffer $100 \mathrm{mM}, \mathrm{pH} 6.5$ in $\mathrm{D}_{2} \mathrm{O}$. In the inset (e), the structure of elenolic acid is illustrated; Figure S3: Magnetic separation of the CS MNPs.

Author Contributions: Conceptualization, H.S.; methodology, A.G., A.V.C., N.C. and H.S.; validation, A.G. and G.T.; investigation, A.G., A.V.C., A.C.P. and H.S.; data curation, A.G., N.C. and D.G.; writing—original draft preparation, A.G. and A.V.C.; writing—review and editing, H.S.; project administration, H.S. and A.C.P.; funding acquisition, H.S. All authors have read and agreed to the published version of the manuscript.

Funding: This research was co-financed by the European Regional Development Fund of the European Union and Greek national funds through the Operational Program Competitiveness, Entrepreneurship and Innovation, under the call 'Aquaculture' - Industrial Materials'-'Open Innovation in Culture' (project: AntiMicrOxiPac, project code: Т6ҮВП-00232).

Data Availability Statement: Data is contained within the article or supplementary material.

Conflicts of Interest: The authors declare no conflict of interest. The funders had no role in the design of the study; in the collection, analyses, or interpretation of data; in the writing of the manuscript, or in the decision to publish the results.

\section{References}

1. Nediani, C.; Ruzzolini, J.; Romani, A.; Calorini, L. Oleuropein, a Bioactive Compound from Olea europaea L., as a Potential Preventive and Therapeutic Agent in Non-Communicable Diseases. Antioxidants 2019, 8, 578. [CrossRef] [PubMed]

2. Yuan, J.-J.; Wang, C.-Z.; Ye, J.-Z.; Tao, R.; Zhang, Y.-S. Enzymatic Hydrolysis of Oleuropein from Olea europea (Olive) Leaf Extract and Antioxidant Activities. Molecules 2015, 20, 2903-2921. [CrossRef]

3. Liu, M.; Yong, Q.; Yu, S. Efficient bioconversion of oleuropein from olive leaf extract to antioxidant hydroxytyrosol by enzymatic hydrolysis and high-temperature degradation. Biotechnol. Appl. Biochem. 2018, 65, 680-689. [CrossRef]

4. De Leonardis, A.; Aretini, A.; Alfano, G.; Macciola, V.; Ranalli, G. Isolation of a hydroxytyrosol-rich extract from olive leaves (Olea Europaea L.) and evaluation of its antioxidant properties and bioactivity. Eur. Food Res. Technol. 2008, 226, 653-659. [CrossRef]

5. Xu, F.; Li, Y.; Zheng, M.; Xi, X.; Zhang, X.; Han, C. Structure Properties, Acquisition Protocols, and Biological Activities of Oleuropein Aglycone. Front. Chem. 2018, 6, 239. [CrossRef] [PubMed]

6. Nikolaivits, E.; Termentzi, A.; Skaltsounis, A.-L.; Fokialakis, N.; Topakas, E. Enzymatic tailoring of oleuropein from Olea europaea leaves and product identification by HRMS/MS spectrometry. J. Biotechnol. 2017, 253, 48-54. [CrossRef] [PubMed]

7. Soler-Rivas, C.; Espín, J.C.; Wichers, H.J. Oleuropein and related compounds. J. Sci. Food Agric. 2000, 80, 1013-1023. [CrossRef] 
8. Ramírez, E.; Brenes, M.; García, P.; Medina, E.; Romero, C. Oleuropein hydrolysis in natural green olives: Importance of the endogenous enzymes. Food Chem. 2016, 206, 204-209. [CrossRef] [PubMed]

9. Chatzikonstantinou, A.V.; Gkantzou, E.; Thomou, E.; Chalmpes, N.; Lyra, K.-M.; Kontogianni, V.G.; Spyrou, K.; Patila, M.; Gournis, D.; Stamatis, H.; et al. Enzymatic Conversion of Oleuropein to Hydroxytyrosol Using Immobilized $\beta$-Glucosidase on Porous Carbon Cuboids. Nanomaterials 2019, 9, 1166. [CrossRef]

10. Giannakopoulou, A.; Gkantzou, E.; Polydera, A.; Stamatis, H. Multienzymatic Nanoassemblies: Recent Progress and Applications. Trends Biotechnol. 2020, 38, 202-216. [CrossRef]

11. Ren, S.; Liu, X.; Jiao, X.; Jia, S.; Jiang, Y.; Bilal, M.; Cui, J. Recent progress in multienzymes co-immobilization and multienzyme system applications. Chem. Eng. J. 2019, 373, 1254-1278. [CrossRef]

12. Filice, M.; Palomo, J.M. Cascade Reactions Catalyzed by Bionanostructures. ACS Catal. 2014, 4, 1588-1598. [CrossRef]

13. Monteiro, R.R.C.; Lima, P.J.M.; Pinheiro, B.; Freire, T.M.; Dutra, L.M.U.; Fechine, L.; Gonçalves, L.R.B.; De Souza, M.C.M.; Dos Santos, J.C.S.; Fernandez-Lafuente, R. Immobilization of Lipase A from Candida antarctica onto Chitosan-Coated Magnetic Nanoparticles. Int. J. Mol. Sci. 2019, 20, 4018. [CrossRef] [PubMed]

14. Chen, Z.; Wang, X.; Chen, Y.; Xue, Z.; Guo, Q.; Ma, Q.; Chen, H. Preparation and characterization of a novel nanocomposite with double enzymes immobilized on magnetic $\mathrm{Fe}_{3} \mathrm{O}_{4}$-chitosan-sodium tripolyphosphate. Colloids Surfaces B Biointerfaces 2018, 169, 280-288. [CrossRef] [PubMed]

15. Gokhale, A.M.; Patel, G.R. Analysis of variability in tensile ductility of a semi-solid metal cast A356 Al-alloy. Mater. Sci. Eng. A 2005, 392, 184-190. [CrossRef]

16. Wu, Y.; Wang, Y.; Luo, G.; Dai, Y. In situ preparation of magnetic $\mathrm{Fe}_{3} \mathrm{O}_{4}$-chitosan nanoparticles for lipase immobilization by cross-linking and oxidation in aqueous solution. Bioresour. Technol. 2009, 100, 3459-3464. [CrossRef] [PubMed]

17. Mohammed, M.A.; Syeda, J.T.M.; Wasan, K.M.; Wasan, E.K. An Overview of Chitosan Nanoparticles and Its Application in Non-Parenteral Drug Delivery. Pharmaceutics 2017, 9, 53. [CrossRef]

18. Díaz-Hernández, A.; Gracida, J.; García-Almendárez, B.E.; Regalado, C.; Núñez, R.; Amaro-Reyes, A. Characterization of Magnetic Nanoparticles Coated with Chitosan: A Potential Approach for Enzyme Immobilization. J. Nanomater. 2018, $2018,1-11$. [CrossRef]

19. Assa, F.; Jafarizadeh-Malmiri, H.; Ajamein, H.; Vaghari, H.; Anarjan, N.; Ahmadi, O.; Berenjian, A. Chitosan magnetic nanoparticles for drug delivery systems. Crit. Rev. Biotechnol. 2016, 37, 492-509. [CrossRef]

20. Barbosa, O.; Ortiz, C.; Berenguer-Murcia, Á.; Torres, R.T.R.; Rodrigues, R.C.; Fernandez-Lafuente, R. Glutaraldehyde in biocatalysts design: A useful crosslinker and a versatile tool in enzyme immobilization. RSC Adv. 2014, 4, 1583-1600. [CrossRef]

21. Monteiro, R.R.; Virgen-Ortiz, J.J.; Berenguer-Murcia, Á; da Rocha, T.N.; dos Santos, J.C.; Alcántara, A.R.; Fernandez-Lafuente, R. Biotechnological relevance of the lipase A from Candida antarctica. Catal. Today 2021, 362, 141-154. [CrossRef]

22. Akın, D.; Yakar, A.; Gündüz, U. Synthesis of Magnetic $\mathrm{Fe}_{3} \mathrm{O}_{4}$-Chitosan Nanoparticles by Ionic Gelation and Their Dye Removal Ability. Water Environ. Res. 2015, 87, 425-436. [CrossRef] [PubMed]

23. Detsi, A.; Kavetsou, E.; Kostopoulou, I.; Pitterou, I.; Pontillo, A.R.N.; Tzani, A.; Christodoulou, P.; Siliachli, A.; Zoumpoulakis, P. Nanosystems for the Encapsulation of Natural Products: The Case of Chitosan Biopolymer as a Matrix. Pharmaceutics 2020, 12, 669. [CrossRef] [PubMed]

24. Cao, C.; Xiao, L.; Chen, C.; Shi, X.; Cao, Q.; Gao, L. In situ preparation of magnetic $\mathrm{Fe}_{3} \mathrm{O}_{4} /$ chitosan nanoparticles via a novel reduction-precipitation method and their application in adsorption of reactive azo dye. Powder Technol. 2014, $260,90-97$. [CrossRef]

25. López-Gallego, F.; Guisán, J.M.; Betancor, L. Glutaraldehyde-Mediated Protein Immobilization. Methods Mol. Biol. 2013, 1051, 33-41. [CrossRef]

26. Giannakopoulou, A.; Patila, M.; Spyrou, K.; Chalmpes, N.; Zarafeta, D.; Skretas, G.; Gournis, D.; Stamatis, H. Development of a Four-Enzyme Magnetic Nanobiocatalyst for Multi-Step Cascade Reactions. Catalysts 2019, 9, 995. [CrossRef]

27. Chen, Q.; Liu, D.; Wu, C.; Yao, K.; Li, Z.; Shi, N.; Wen, F.; Gates, I.D. Co-immobilization of cellulase and lysozyme on aminofunctionalized magnetic nanoparticles: An activity-tunable biocatalyst for extraction of lipids from microalgae. Bioresour. Technol. 2018, 263, 317-324. [CrossRef]

28. Sojitra, U.V.; Nadar, S.; Rathod, V.K. A magnetic tri-enzyme nanobiocatalyst for fruit juice clarification. Food Chem. 2016, 213, 296-305. [CrossRef]

29. Muley, A.B.; Thorat, A.S.; Singhal, R.S.; Babu, K.H. A tri-enzyme co-immobilized magnetic complex: Process details, kinetics, thermodynamics and applications. Int. J. Biol. Macromol. 2018, 118, 1781-1795. [CrossRef]

30. Pavlidis, I.V.; Vorhaben, T.; Gournis, D.; Papadopoulos, G.K.; Bornscheuer, U.T.; Stamatis, H. Regulation of catalytic behaviour of hydrolases through interactions with functionalized carbon-based nanomaterials. J. Nanopart. Res. 2012, 14, 1-10. [CrossRef]

31. Tzialla, A.A.; Pavlidis, I.V.; Felicissimo, M.P.; Rudolf, P.; Gournis, D.; Stamatis, H. Lipase immobilization on smectite nanoclays: Characterization and application to the epoxidation of $\alpha$-pinene. Bioresour. Technol. 2010, 101, 1587-1594. [CrossRef]

32. Verma, M.L.; Rao, N.M.; Tsuzuki, T.; Barrow, C.J.; Puri, M. Suitability of Recombinant Lipase Immobilised on Functionalised Magnetic Nanoparticles for Fish Oil Hydrolysis. Catalysts 2019, 9, 420. [CrossRef]

33. Verma, M.L.; Naebe, M.; Barrow, C.; Puri, M. Enzyme Immobilisation on Amino-Functionalised Multi-Walled Carbon Nanotubes: Structural and Biocatalytic Characterisation. PLoS ONE 2013, 8, e73642. [CrossRef] 
34. Chatzikonstantinou, A.V.; Polydera, A.C.; Thomou, E.; Chalmpes, N.; Baroud, T.N.; Enotiadis, A.; Estevez, L.; Patila, M.; Hammami, M.A.; Spyrou, K.; et al. Lipase immobilized on magnetic hierarchically porous carbon materials as a versatile tool for the synthesis of bioactive quercetin derivatives. Bioresour. Technol. Rep. 2020, 9, 100372. [CrossRef]

35. Li, L.; Li, H.; Yan, B.; Yu, S. Preparation of a reversible soluble-insoluble $\beta$-d-Glucosidase with perfect stability and activity. $J$. Biotechnol. 2019, 291, 46-51. [CrossRef] [PubMed]

36. Girard-Egrot, A.P.; Godoy, S.; Blum, L.J. Enzyme association with lipidic Langmuir-Blodgett films: Interests and applications in nanobioscience. Adv. Colloid Interface Sci. 2005, 116, 205-225. [CrossRef] [PubMed]

37. Paudyal, S.; Sharma, S.K.; da Silva, R.L.; Mintz, K.J.; Liyanage, P.Y.; Al-Youbi, A.O.; Bashammakh, A.S.; El-Shahawi, M.S.; Leblanc, R.M. Tyrosinase enzyme Langmuir monolayer: Surface chemistry and spectroscopic study. J. Colloid Interface Sci. 2020, 564, 254-263. [CrossRef] [PubMed]

38. Ayoub, F.D.P.; Caseli, L. Controlling the molecular architecture of lactase immobilized in Langmuir-Blodgett films of phospholipids to modulate the enzyme activity. Colloids Surfaces B Biointerfaces 2017, 150, 8-14. [CrossRef]

39. Chapman, J.; Ismail, A.E.; Dinu, C.Z. Industrial Applications of Enzymes: Recent Advances, Techniques, and Outlooks. Catalysts 2018, 8, 238. [CrossRef]

40. Gupta, P.; Verma, S.; Vakhlu, J. Comparative Analysis of B- Glucosidases Thermostability: Differences in Amino Acids Composition and Distribution among Mesostable and Thermostable B-Glucosidases. J. Adv. Bioinform. Appl. Res. 2014, 5, $215-227$.

41. Shahrestani, H.; Taheri-Kafrani, A.; Soozanipour, A.; Tavakoli, O. Enzymatic clarification of fruit juices using xylanase immobilized on 1,3,5-triazine-functionalized silica-encapsulated magnetic nanoparticles. Biochem. Eng. J. 2016, 109, 51-58. [CrossRef]

42. Alnadari, F.; Xue, Y.; Zhou, L.; Hamed, Y.S.; Taha, M.; Foda, M.F. Immobilization of $\beta$-Glucosidase from Thermatoga maritima on Chitin-functionalized Magnetic Nanoparticle via a Novel Thermostable Chitin-binding Domain. Sci. Rep. 2020, 10 , 1-12. [CrossRef] [PubMed]

43. Bradford, M.M. A rapid and sensitive method for the quantitation of microgram quantities of protein utilizing the principle of protein-Dye binding. Anal. Biochem. 1976, 72, 248-254. [CrossRef]

44. Whitmore, L.; Wallace, B.A. DICHROWEB, an online server for protein secondary structure analyses from circular dichroism spectroscopic data. Nucleic Acids Res. 2004, 32, W668-W673. [CrossRef] [PubMed]

45. Lobley, A.; Whitmore, L.; Wallace, B.A. DICHROWEB: An interactive website for the analysis of protein secondary structure from circular dichroism spectra. Bioinformatics 2002, 18, 211-212. [CrossRef] [PubMed]

46. Bowers, G.N., Jr.; McComb, R.B.; Christensen, R.G.; Schaffer, R. High-purity 4-nitrophenol: Purification, characterization, and speci-fications for use as a spectrophotometric reference material. Clin. Chem. 1980, 26, 724-729. [CrossRef] 